\title{
Celebrating 50 Years of Publication!
}

\author{
Daniel J. Call ${ }^{1} \cdot$ Joseph W. Gorsuch ${ }^{2}$
}

Received: 1 December 2015/Accepted: 7 December 2015/Published online: 15 December 2015

(C) Springer Science+Business Media New York 2015

We are honored to introduce this issue as the first in the Golden Anniversary year of the Bulletin of Environmental Contamination and Toxicology. Several changes during 2016 may be noted in commemoration of this special year. For example, the Bulletin's cover has been changed from the traditional orange to gold. Editorials by former and present editors-in-chief will appear in several of the forthcoming issues. These editorials will reflect on the history and expansion of the journal. Several past authors have offered to contribute articles on the advancement of science and regulations to protect the environment, and some of the general articles that are published may be flavored with a bit more historical perspective than usual.

The first issue of the Bulletin was published in 1966, at a time when chemicals such as chlorinated pesticides were common subject matter. Analytical instruments were archaic by current standards, and computerization of laboratory instruments and libraries was essentially in its infancy. The internet and digital publishing did not yet exist. Many of the environmental organizations and regulatory agencies that exist around the world today had not yet been formed. The 1970s, a decade for passage of major environmental laws in the United States, was still a few years ahead. Some universities and colleges were only starting to consider the offering of environmental science, environmental engineering or environmental toxicology as majors. It was a time when the environment had become seriously

Daniel J. Call

dcall@enviro-analysts.com

1 Environmental Research and Information Analysts, Dubuque, IA 52001, USA

2 Gorsuch Environmental Management Services, Webster, NY 14580, USA polluted by a host of chemicals, and the demand existed to address these issues. Fortunately, certain far-sighted individuals saw the need for a vehicle to provide rapid communication amongst scientists involved in analyzing the contaminants and studying their effects upon the biota. It was in this setting that the Bulletin was launched.

As the Bulletin became known among scientists, more articles were submitted for publication, and the journal expanded from the original six issues per year to twelve. The physical size of the pages grew, as well as the number of pages per issue, to accommodate the rapidly expanding field of environmental contamination and toxicology. The demographics of authorship also changed over time. A recent analysis (Drouillard and Bennett 2015) of the most highly cited papers in the Bulletin revealed that North American authors predominated for about the first 30 years, with highly cited contributions from Europe, Asia, and the Middle East increasing in number during this period. For the most recent period for which data were included in their study (2004-2009), the order for region of origin of the 50 top-cited papers was Asia, North America, Middle East, Europe, South America and Australia. This analysis has demonstrated the increasingly global nature of the Bulletin in its authorship over time. The Bulletin is truly a well recognized international journal today.

In the inaugural issue of the journal (Editorial Board 1966), it was stated in the "Aims and Scope" that the Bulletin "will provide rapid publication of significant advances and discoveries in the fields of pesticide research, air, soil and water contamination and pollution, methodology, and other disciplines concerned with the introduction, presence and effects of toxicants in the total environment." Articles suitable for publication were to be short, of less than 2000 words. While the wording has evolved some (see "Aims and Scope" for 2015; www. 
springer.com/), the goal of rapid communication of short articles has remained as a mainstay of the Bulletin.

We extend our thanks to all of the individuals who have contributed to the development and success of the Bulletin over these 50 years. This list includes the staff of Springer Publishers, editors-in-chief, editors, peer reviewers, authors and readers. At the same time, we look forward to the future with the publication of new articles that will continue to advance our knowledge of chemical contaminants and their effects. In this light, we invite readers of this issue to consider contributing an article on their research for potential publication during this Golden Anniversary year.

We wish the journal continued success as it embarks on its next 50 years!
Daniel J. Call and Joseph W. Gorsuch

Anniversary Volume Editors

\section{References}

Aims and Scope. www.springer.com/environment/pollution + and + re mediation/journal/128. Accessed 19 Nov 2015

Drouillard KG, Bennett ER (2015) The changing face of BECT. A citation analysis covering 1966-2009. Bull Environ Contam Toxicol 94:1-5. doi:10.1007/s00128-014-1438-8

Editorial Board (1966) Aims and scope. Bull Environ Contam Toxicol 1(1):4 